\title{
Features of hemodynamics of pulmonary circulation during the diving reflex
}

\section{Ekaterina Podyacheva ${ }^{1}$, Tatyana Zemlyanukhina ${ }^{1}$, Lavrentij Shadrin'², and Tatyana Baranova ${ }^{1}$}

1Department of General Physiology, Faculty of Biology, Saint Petersburg State University, Universitetskaya nab., 7-9, Saint Petersburg, 199034, Russian Federation

2Department of Physical Culture and Sports, Saint Petersburg State University, Universitetskaya nab., 7-9, Saint Petersburg, 199034, Russian Federation

Address correspondence and requests for materials to Ekaterina Podyacheva, katrinstanford@gmail.com

\begin{abstract}
The adaptive cardiovascular reactions of the human diving reflex were studied. The diving reflex was activated by submerging a face in cold water under laboratory conditions. Forty volunteers (aged 18-24) were examined. ECG, arterial blood pressure (ABP) and central blood flow were recorded by the impedance rheography method in resting state, during diving simulation (DS) and after apnea. During DS there is a statistically significant decrease in the dicrotic index $(\mathrm{DCl})$, which reflects a decrease in the resistive vessel tone and as well as diastolic index (DSI), characterizing lung perfusion. A comparison of the latent periods (LP) of an increase in $A B P$ and a drop in $D C l$ showed that a decrease in pulmonary vascular tone develops faster than ABP begins to increase. The LP for lowering $D C l$ is from 0.6 to $10 \mathrm{~s}$; for an increase in $A B P$ - from 6 to $30 \mathrm{~s}$. A short LP for $\mathrm{DCl}$ and the absence of a correlation between a decrease in ABP and $\mathrm{DCl}$ suggests that a decrease in pulmonary vascular tone during DS occurs reflexively and independently of a change in ABP.
\end{abstract}

Keywords: diving reflex, systemic circulation, pulmonary circulation, impedance rheography, plethysmography.

\section{Introduction}

Shadrin, L., and Baranova, T. 2020. Features of hemodynamics of pulmonary circulation during the diving reflex. Bio. Comm. 65(3): 244-251. https://doi.org/10.21638/ spbu03.2020.304

Authors' information: Ekaterina Podyacheva, Master of Sci. in Biology, Student, orcid.org/0000-0002-0365-3301; Tatyana Zemlyanukhina, Master of Sci. in Biology, Student, orcid.org/0000-00032651-8521; Lavrentij Shadrin, PhD, Head of Laboratory, orcid.org/0000-0003-0199-4417; Tatyana Baranova, Dr. of Sci. in Biology, Researcher, orcid.org/0000-0003-0524-2933

Manuscript Editor: Michael Firsov, Sechenov Institute of Evolutionary Physiology and Biochemistry, Russian Academy of Sciences, Saint Petersburg, Russia

Received: December 9, 2019;

Revised: June 5, 2020;

Accepted: June 25, 2020.

Copyright: @ 2020 Podyacheva et al. This is an open-access article distributed under the terms of the License Agreement with Saint Petersburg State University, which permits to the authors unrestricted distribution, and self-archiving free of charge.

Funding: No funding information provided.
Resistance to extreme environmental factors is determined by the adaptive potential of the body, its protective mechanisms. One of these mechanisms is the diving reflex inherent in humans and animals (Ilardo, 2018). The diving reflex is an interconnected set of respiratory and cardiovascular signaling reflexes aimed at economizing oxygen consumption while diving (Campbell et al, 1969; Ponganis, 2011).

In both animals and humans, when the head is immersed in water, breathing reflexively stops, heart rhythm decelerates, and constriction occurs in the peripheral vessels of the skin, muscles, and the gastrointestinal tract (Ramirez et al., 2007). Blood is redistributed to those organs which are most vulnerable to hypoxia (the brain, heart and lungs) (Andersen, 1966; Galantsev, 1977, 1982, 1986; Elsner et al., 1964; Elsner, 1970; Thompson et al., 1993; Butler et al., 2007). The peculiarities of the realization of this reflex in animals are determined by species, and in humans are determined by features of vegetative regulation and psychophysiological status (Galantsev, 1995; Baranova, 2004).

The phenomenon of the diving reflex has been described quite well, but the mechanisms of the diving reflex are complicated and still far from full understanding. For example, there are conflicting data about blood flow in pulmonary circulation during diving (or diving simulation). According to some researchers, blood flow decreases in the lungs and oxygen extraction decreases from the lungs (Anderssen et al., 1998). At first glance, this seems reasonable, since hypoxia, hy- 
percapnia and a decrease in $\mathrm{pH}$ provoke constriction of the pulmonary vessels (Dawson, 1984). Data from other researchers, in contrast, indicate dilatation of the pulmonary vessels when diving. The authors explain this by the fact that filling the lungs with blood prevents the compression of the alveoli (Linér et al., 2008), but they are convinced that the cause of this effect is the barometric factor. Pulmonary capillary stress failure represents a continuum of conditions from a low-permeability, hydrostatic type of pulmonary edema at slightly elevated capillary pressures, to a high-permeability form of edema or even frank hemorrhage at high capillary pressures (West et al., 1991, 1992). It is believed (Linér et al., 2008) that the mechanism of these disorders is associated with an increase in intrathoracic blood volume and, consequently, the increase of pulmonary capillary transmural pressure. With the usual holding of breath without immersion in water during inspiration, the intrathoracic pressure is increased relative to ambient due to the elastic inward recoil of the chest wall (Ferrigno et al., 1987). The increased intrathoracic pressure hinders venous return, resulting in decreased pulmonary blood flow and cardiac output, as well as decreased intrathoracic blood volume, cardiovascular changes that would not bring about pulmonary edema. In contrast, when a breathhold diver descends to depth during a dive, the lung gas volume decreases due to increased ambient pressure, according to Boyle's law. When the lung gas volume decreases, the intrathoracic pressure drops relative to ambient pressure. This depth-related drop in intrathoracic pressure results in increased venous return, pulmonary blood flow, and cardiac output, as well as increased intrathoracic blood volume compared with breath holding without immersion in water. These changes cause the pulmonary capillary transmural pressure to increase, leading to the development of pulmonary edema.

The aim of this study was to study hemodynamics (in particular, pulmonary blood flow) during diving simulation by immersing the face in chilled water. Such a model of diving simulation is usually used to study this phenomenon in laboratory conditions (Scholander, 1962; Elsner et al., 1963; Irving, 1963; Gooden, 1994; Andersson et al., 1998, 2002, 2004). We suggest that during diving simulation, the tone of the pulmonary vessels can change under the influence of local reflex reactions, regardless of the processes taking place in systemic circulation.

\section{Materials and methods}

Materials. Forty healthy volunteers (aged 18-24; 11 males, 29 females) without special physical training were included in the study. All of the subjects (students of the Saint Petersburg State University, Russia) participated in the study voluntarily and had no direct benefit from the test (financial rewards, educational requirements or credits). Information about the general results of the research or personal data was provided to interested individuals. At the time of the experiment, none of the volunteers had arteriosclerosis or diabetes or were taking any drugs. The study was approved by the Saint Petersburg State University Ethics Review Committee for human studies (No. 40 from 07.03.2012), and all of the volunteers signed an informed agreement.

Exposures and sampling procedures. The activation of the diving reflex was performed using face submersion in cold water under laboratory conditions (diving simulation). It is well known that a $10^{\circ} \mathrm{C}$ gradient between the air temperature and the water temperature is optimal for the manifestation of the diving reflex (Glotov et al., 2007), and in our experiments, the water temperature was $13.2 \pm 0.4^{\circ} \mathrm{C}$ and the air temperature was $22.6 \pm 0.3^{\circ} \mathrm{C}$. The procedure was performed on subjects lying in a ventricumbent position on a couch with their arms along their body (Fig. 1). During the experimental procedure, all of the subjects kept their hands at the heart line, did not change this position, and did not move their fingers with a finger sensor. Six face submersions on a normal exhale were performed in cold water. The duration of the first submersion was limited by the feeling of first discomfort. The duration of the remaining submersions was performed on volitional breath-hold until a maximum time. The pause between submersions was from 2 to $3 \mathrm{~min}$.

Electrocardiogram records were taken for the resting state, during diving simulation and after apnea. During the whole experiment, heart rate was continuously recorded with the Poly-Spectrum-8/E Superminiature 12-channel Digital ECG System (by Neurosoft). Arterial blood pressure was recorded with a sphygmomanometer with the cuff on the right shoulder (B. Well WA-33). Also, arterial blood pressure was measured using the Finometer-pro (FMS, Holland) throughout the diving simulation procedure. The minute volume of blood flow (MVBF, liter per min $(1 / \mathrm{min}))$ and the stroke volume (SV, $\mathrm{ml})$ were determined for these states using the impedance rheography method (RGPA-6/12 "Rean-Poly," Medicom-MTD, Russia). Blood supply to peripheral vessels was measured indirectly using the pulse wave amplitude (PWA, per mille (pm)) (Korpas et al., 2009), which was calculated based on the photoplethysmogram records using "Rean-Poly" software (Elite version). The photoplethysmogram method records changes in the tissue optical density, which depends on the blood supply. The rheographic index (RI, Ohm), diastolic index (DSI, \%) and dicrotic index (DCI, \%) were determined also using the impedance method for investigation of right pulmonary artery blood flow (RPABF) (Palko, 2007). The rheographic index characterizes the intensity of arterial blood flow in the lung. The diastolic 


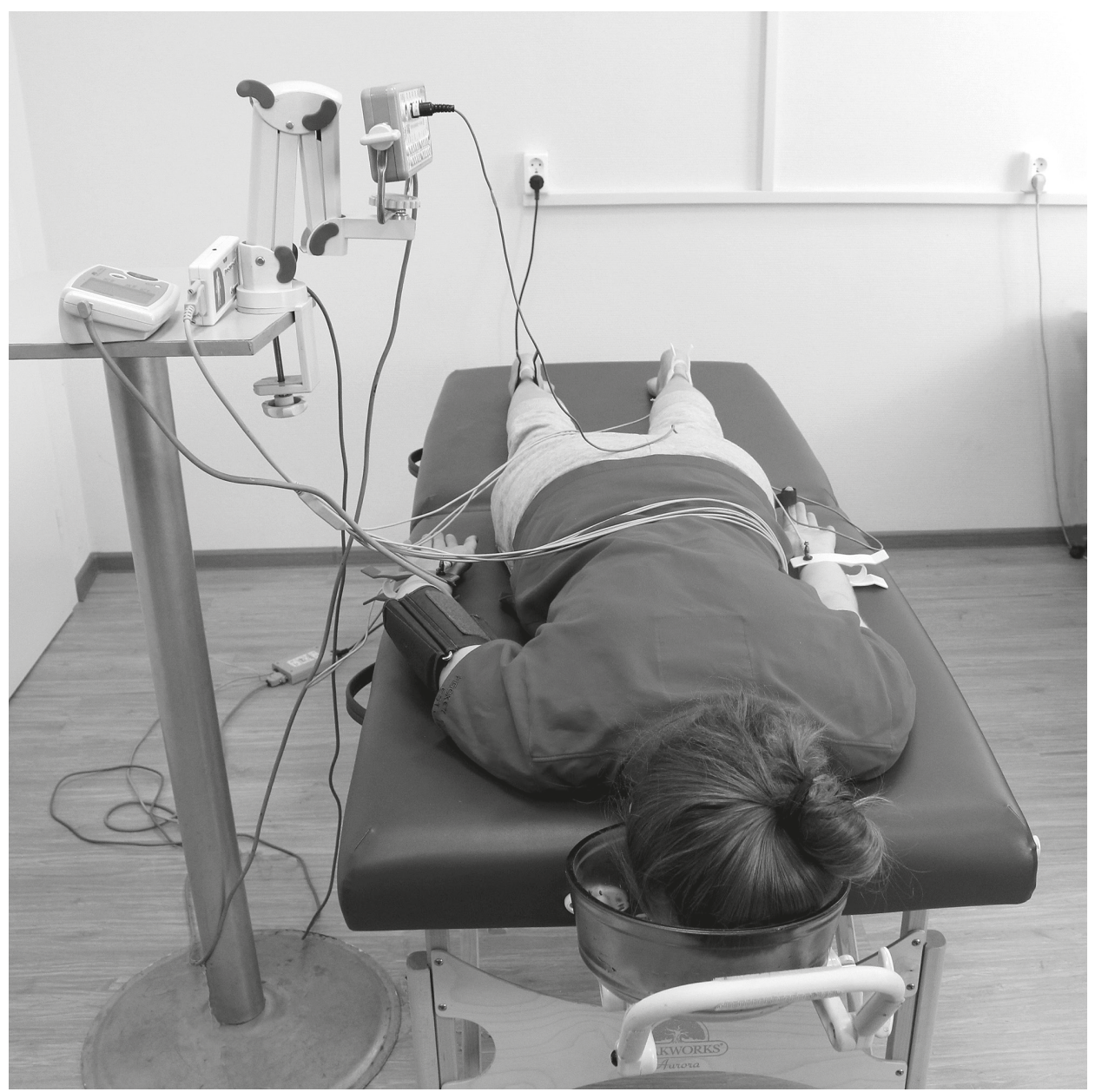

Fig. 1. Scheme of the experiment.

index reflects the ratio of venous outflow of blood to arterial inflow. The dicrotic index mainly characterizes the tone of the resistive vessels of the lungs (Zenkov and Ronkin, 1991).

Statistical analysis. The values are expressed as means and SDs. The statistical analysis was performed using the statistical package for Windows 7 (MS Excel 2010, Origin Pro 2015 version b9.2). A T-test was calculated to assess the significance of differences in samples with normal distribution. $\mathrm{P}$ values $<0.05$ were considered to be statistically significant.

\section{Results}

Analysis of parameters for the whole group. An analysis of the characteristics of systemic hemodynamics showed that the subjects under diving simulation experience statistically significant changes in these parameters: deceleration of heart rhythm (in $82.5 \%$ ), constriction of peripheral vessels (84.2\%), decreased MVBF (in 85.6\%), increased systolic and diastolic blood pressure (SBP in $100 \%$, DBP in $93.3 \%$ of cases) (Fig. 2, 3).
Analysis of pulmonary blood flow parameters revealed a statistically significant decrease in pulmonary vasoconstriction (DCI decreases in $79.37 \%$ of cases, DSI decreases in $78.8 \%$ of cases).

Despite the unidirectional nature of the group as a whole, the nature of the changes in the considered parameters can vary greatly when individually considered.

There are no statistically significant changes in the $\mathrm{SV}$ and the RI in the group as a whole. SV increases in $46 \%$ of cases, and RI increases in $57.1 \%$ of cases (Table 1,2).

Anthropometric parameters of the group were as follows: height $-169.15 \pm 1.26 \mathrm{~cm}$, weight $-61.9 \pm 1.7 \mathrm{~kg}$.

Analysis of pulmonary blood flow. The impedance rheogram of right pulmonary artery blood flow shows the blood filling of the right pulmonary artery and its branches, as well as the emptying of the pulmonary veins during the cardiac cycle. The Rheographic Index (RI) reflects the filling of the right pulmonary artery during the expulsion of blood by the right ventricle. Normally, in healthy people it is $0.15-0.25 \mathrm{Ohms}$. The RI is slightly higher than normal in the volunteers examined by us. 


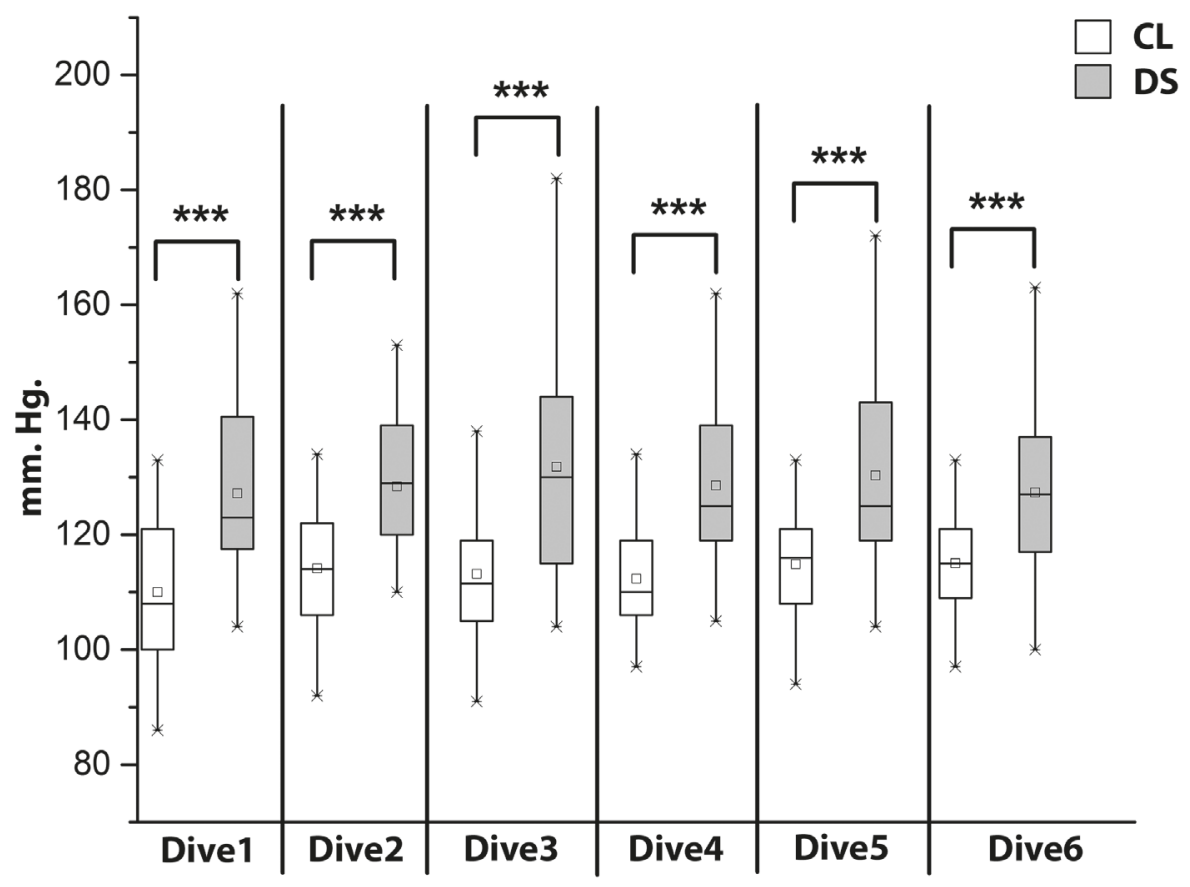

Fig. 2. The dynamics of systolic blood pressure in the subjects with diving simulation. $\mathrm{CL}$ - the control level, DS - the diving simulation. The significance of differences was estimated using Student's t-test: $* * *-p<0.001$ between $C L$ and during dive.

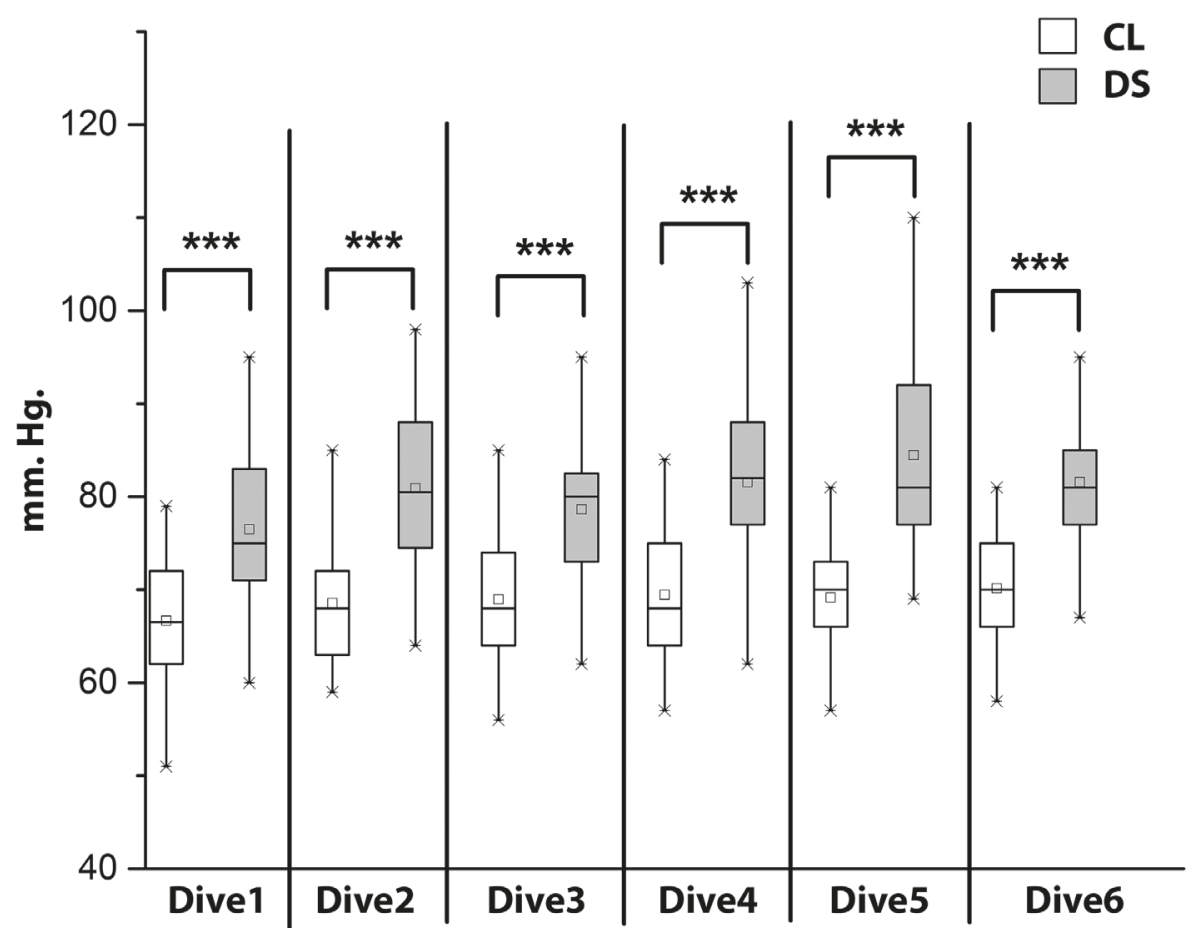

Fig. 3. The dynamics of diastolic blood pressure in the subjects with diving simulation. $\mathrm{CL}-$ the control level, DS - the diving simulation. The significance of differences was estimated using Student's t-test: ${ }^{* *}-\mathrm{p}<0.001$ between $\mathrm{CL}$ and during dive.

The DCI index mainly reflects the tone of the arteries of medium and small caliber (resistive arteries). Normally, its change ranges from $40-70 \%$. The DSI characterizes the outflow of blood from the pulmonary veins; the boundaries of the norm of its oscillations are 50-60\%. Both of these parameters are within normal limits. The volunteers examined by us were mainly characterized by a large systolic ejection of the right ventricle, high elas- 


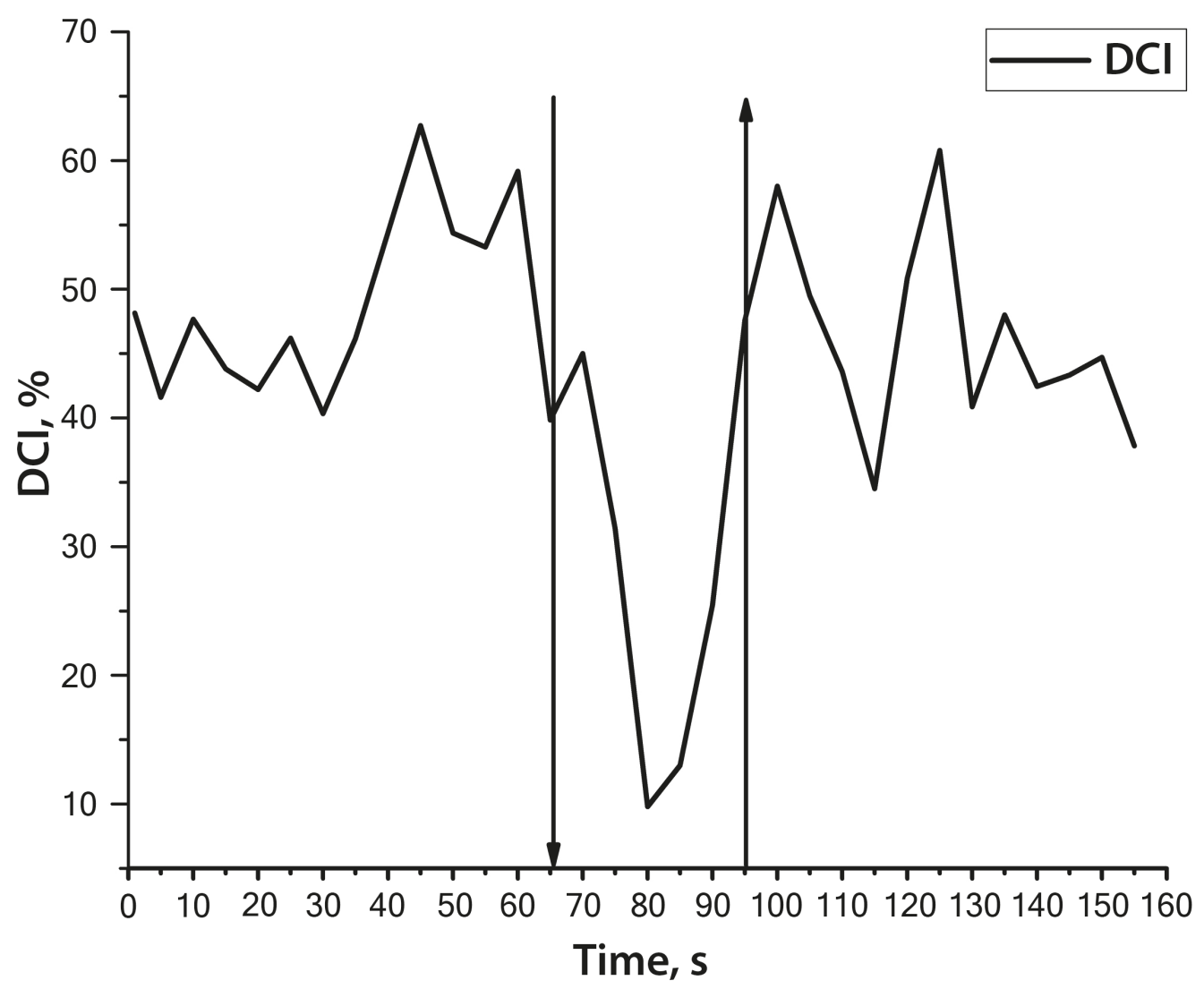

Fig. 4. Example of the latent period of a decrease in the DCl parameter during diving simulation. The arrows indicate the beginning and end of apnea.

Table 1. Dynamics of parameters of minute volume of blood flow (MVBF) and stroke volume (SV) in the subjects with diving simulation

\begin{tabular}{l|c|c|c|c|c|c|c|c|c}
\hline \multicolumn{1}{c|}{ Parameter } & $\mathrm{CL}_{1}$ & $\mathrm{DS}_{1}$ & $\mathrm{Rec}_{1}$ & $\mathrm{CL}_{2}$ & $\mathrm{DS}_{2}$ & $\mathrm{Rec}_{2}$ & $\mathrm{CL}_{3}$ & $\mathrm{DS}_{3}$ & $\mathrm{Rec}_{3}$ \\
\hline $\mathrm{HR}$, beats/min & $66.9 \pm 1.9$ & $64.3 \pm 2.4$ & $69.1 \pm 2.3$ & $71.4 \pm 1.6$ & $60.4 \pm 1.8^{* *}$ & $71.7 \pm 2.8$ & $72.9 \pm 1.6$ & $60.5 \pm 1.9 * *$ & $68.2 \pm 1.7$ \\
\hline $\mathrm{MVBF}, \mathrm{I} / \mathrm{min}$ & $6.62 \pm 0.30$ & $6.01 \pm 0.44$ & $6.42 \pm 0.27$ & $6.45 \pm 0.28$ & $5.33 \pm 0.30 * *$ & $6.11 \pm 0.24$ & $6.73 \pm 0.26$ & $5.5 \pm 0.28 * *$ & $6.41 \pm 0.28$ \\
\hline $\mathrm{SV}, \mathrm{ml}$ & $89.69 \pm 3.10$ & $92.99 \pm 4.19$ & $94.18 \pm 3.23$ & $89.85 \pm 3.31$ & $88.46 \pm 3.47$ & $91.60 \pm 2.97$ & $92.30 \pm 3.17$ & $91.40 \pm 4.13$ & $95.96 \pm 3.47$ \\
\hline $\mathrm{PWA}, \mathrm{pm}$ & $0.73 \pm 0.11$ & $0.31 \pm 0.03^{* * *}$ & $0.76 \pm 0.1$ & $0.6 \pm 0.09$ & $0.38 \pm 0.08^{*}$ & $0.77 \pm 0.13$ & $0.54 \pm 0.08$ & $0.27 \pm 0.03^{* *}$ & $0.68 \pm 0.11$ \\
\hline
\end{tabular}

Note: MVBF — the minute volume of blood flow, SV - the stroke volume, PWA - the pulse wave amplitude, $\mathrm{CL}_{1,2,3}-$ the control level for 1,2 , 3 times of dive, $\mathrm{DS}_{1,2,3}$ - the diving simulation for $1,2,3$ times of dive, $\operatorname{Rec}_{1,2,3}$ - the recovery for $1,2,3$ times of dive. * - significant difference (Student's t-test, $*-p<0.05 ; * *-p<0.01 ; * * *-p<0.001$ ) between $C L$ and during $D S\left(D_{1}\right.$ and $C L_{1}$, etc.).

Table 2. Parameter of the impedance method for investigation of RPABF in the subjects with diving simulation

\begin{tabular}{l|c|c|c|c|c|c|c|c|c}
\hline Parameter & $\mathrm{CL}_{1}$ & $\mathrm{DS}_{1}$ & $\mathrm{Rec}_{1}$ & $\mathrm{CL}_{2}$ & $\mathrm{DS}_{2}$ & $\mathrm{Rec}_{2}$ & $\mathrm{CL}_{3}$ & $\mathrm{DS}_{3}$ & $\mathrm{Rec}_{3}$ \\
\hline $\mathrm{Rl}, \mathrm{Ohm}$ & $0.34 \pm 0.03$ & $0.34 \pm 0.02$ & $0.33 \pm 0.02$ & $0.31 \pm 0.01$ & $0.32 \pm 0.01$ & $0.32 \pm 0.01$ & $0.31 \pm 0.01$ & $0.31 \pm 0.01$ & $0.31 \pm 0.01$ \\
\hline $\mathrm{DCl} \%$ & $60.36 \pm 1.61$ & $47.71 \pm 2.45 * * *$ & $58.22 \pm 1.66$ & $60.61 \pm 1.70$ & $47.59 \pm 1.90 * * *$ & $59.27 \pm 1.46$ & $59.15 \pm 1.58$ & $50.66 \pm 2.03 * * *$ & $57.63 \pm 1.48$ \\
\hline $\mathrm{DSI}, \%$ & $61.98 \pm 1.74$ & $51.53 \pm 2.22 * * *$ & $62.52 \pm 1.60$ & $62.14 \pm 1.71$ & $50.91 \pm 2.07 * * *$ & $63.81 \pm 1.6$ & $61.25 \pm 1.63$ & $53.8 \pm 2.04 * *$ & $62.96 \pm 1.61$ \\
\hline
\end{tabular}

Note: RI - Rheographic index, DSI - diastolic index, $\mathrm{DCl}$ - dicrotic index, $\mathrm{CL}_{1,2,3}$ - the control level for 1, 2, 3 times of dive, $\mathrm{DS}_{1,2,3}-$ the diving simulation for 1, 2, 3 times of dive, $\operatorname{Rec}_{1,2,3}$ - the recovery for 1, 2, 3 times of dive. * - significant difference (Student's t-test, ${ }^{\star \star}-p<0.01$; $* \star * \ldots p<0.01$ ) between $\mathrm{CL}$ and during DS (DS1 and CL1, etc.). 
ticity of the pulmonary artery against the background of normal or slightly reduced vascular tone, and good outflow from the pulmonary veins. This can be explained by the fact that the subjects were young. During diving simulation in both groups, there is a statistically significant decrease in the DCI, which reflects a decrease in the tone of the resistive vessels and a decrease in the DSI, which indicates an increase in the outflow from the pulmonary veins (Table 2). The latent period of a decrease in the DCI parameter during diving simulation develops from 0.6 to $10 \mathrm{~s}$. (Fig. 4). The latent period of increasing blood pressure is from 6 to $30 \mathrm{~s}$ for SBP and from 6.8 to $43.5 \mathrm{~s}$ for DBP.

Two phases can be identified when diving simulation lasts in excess of 30 seconds. The first phase (easily proceeding) is characterized by a progressive decrease in heart rate. The second phase (voltage phase) is accompanied by a slight increase in heart rate (Baranova et al., 2004). We have shown that DCI is in direct reliable correlation with heart rate. We see two phases in Figure 4 . The first is accompanied by a decrease in DCI, the second phase - an increase in DCI, which is probably associated with increased adrenergic effects on the pulmonary vessels in the second phase.

\section{Discussion}

The diving reflex is a protective mechanism that has developed during evolution during adaptation to diving in secondary aquatic amniotes and humans. It is realized at the biochemical, neuroimmune endocrine and physiological levels. The diving reflex is triggered by reflex apnea that occurs when the face of humans or head of aquatic mammals is immersed in water. Further, trigiminal reflex, glossopharyngeal reflex, baroreflex, depressive reflex of the synocaratid zones reflexes are triggered by the reflex fields of the skin, mucous membranes of the nasopharynx, chemo- and baroceptors of the vascular bed, causing increased vagal influences on the heart (McCulloch et al., 2018). The cholinergic effects of parasympathetic neurons on the muscarinic M2 receptors of atrial cardiomyocytes and cells of the sinoatrial and atrioventricular nodes cause a slowed heart rate, which leads to a deceleration in blood flow, a decrease in its minute volume of blood flow and, as a result, a slowing of oxygen consumption. At the same time, there is an increase in the tone of the pressor section of the vasomotor center of the medulla oblongata due to the receipt of signals from the chemoreceptors of the vascular bed. An increase in the sympathetic noradrenergic effects on the alpha-1 receptors of muscle cells of peripheral vessels leads to a constriction of the vessels of the skin and organs of the gastrointestinal tract. Blood flow is redistributed to the lungs, heart, and brain (Heusser et al., 2009; Baranova et al., 2017).
Under physiological conditions of rest, normal vascular tone is determined by the optimal ratio of the production of endothelial vasodilating and vasoconstrictor substances, which is fully consistent with the metabolic needs of the body.

Pulmonary circulation has its own characteristics compared with systemic circulation, both in structure and in regulation. Pulmonary vessels have high extensibility, since their vascular wall is much thinner than that of skeletal muscles. It is this that determines the role of the pulmonary vessels as a blood depot, and this ensures the maintenance of adequate pulmonary gas exchange. It is also important to consider that the vessels of pulmonary circulation are a low pressure system. The average pressure in the human pulmonary artery is $15-25 \mathrm{~mm}$. $\mathrm{Hg}$., and the pressure in human pulmonary veins is 6-8 mm. Hg. Another role of the high extensibility of pulmonary vessels is as follows: a significant increase in blood flow in pulmonary circulation (for example, during physical exertion) is not accompanied by an increase in arterial blood pressure in systemic circulation.

Pulmonary vessels are innervated by sympathetic vasoconstrictor, sympathetic vasodilator, and parasympathetic cholinergic fibers and are under the constant influence of the autonomic nervous system. However, the influence of the nervous system on the pulmonary vessels is less pronounced, in contrast to the vessels of systemic circulation. The most reflexogenic zone is the large pulmonary vessels (right pulmonary artery) (Vaillancourt, 2017).

It is noted that pulmonary veins are a functional reservoir of blood for the cardiovascular system. Sympathetic vasoconstriction of the pulmonary veins can be essential for mobilizing a given volume of blood under general stress conditions of the cardiovascular system (Morman and Heller, 2000).

It is known that reflexes of self-regulation of blood circulation from the baro- and chemoreceptors of the carotid sinus are accompanied by active changes in pulmonary circulation. When baroreceptors of the carotid sinus are excited due to an increase in arterial blood pressure, a decrease in the resistance of blood vessels of pulmonary circulation occurs reflexively, which leads to an increase in blood supply to the lungs and normalization of pressure in systemic circulation. When the baroreceptors of the pulmonary artery are excited, which occurs when the pressure in pulmonary circulation increases, the pressure in systemic circulation decreases reflexively due to the deceleration of the heart's rhythm and the expansion of the vessels of systemic circulation (Parin's reflex).

An investigation of pulmonary blood flow revealed a statistically significant decrease in the tone of pulmonary vessels during diving simulation. In this case, apparently, this occurs reflexively in the same way as constric- 
tion of the peripheral vessels of systemic circulation and reflex bradycardia. Decreased tone of pulmonary vessels is an integral part of the diving reflex. On the one hand, the mechanism of interaction of systemic and pulmonary circulation during the implementation of the diving reflex can be described as follows: The vessels of the lungs, like the vessels of systemic circulation, are under constant tonic influence of the sympathetic nervous system. When baroreceptors of the carotid sinus are excited due to an increase in the arterial blood pressure during the implementation of the diving reflex, an increase in the arterial blood pressure occurs due to constriction of peripheral vessels, which leads to a decrease in the resistance of the pulmonary circulation vessels. A decrease in the resistance of the pulmonary vessels occurs due to a decrease in sympathetic influences, which leads to an increase in blood supply to the lungs and normalization of pressure in pulmonary circulation.

In our study, an increase in blood pressure is observed towards the middle of apnea or towards its end, while a decrease in pulmonary vascular tone occurs at the beginning of the implementation of the diving reflex. In this regard, it can be assumed that a decrease in the tone of the vessels of the pulmonary circulation is a reflex process that is independent of blood pressure. In humans, though, this process is probably associated with the peculiarities of the autonomic regulation of the vessels of pulmonary circulation, namely, the influence of parasympathetic cholinergic fibers.

Thus, for the first time, a reflexive decrease of the tone of vessels of the pulmonary artery during diving simulation was shown. However, these facts require a deeper theoretical understanding and confirmation on a larger sample.

\section{References}

Andersson, J. and Schagatay, E. 1998. Effects of lung volume and involuntary breathing movements on the human diving response. European Journal of Applied Physiology and Occupational Physiology 77(1-2):19-24. https://doi. org/10.1007/s004210050294

Andersson, J. P., Biasoletto-Tjellstrom, G., and Schagatay, E. K. 2008. Pulmonary gas exchange is reduced by the cardiovascular diving response in resting humans. Respiratory Physiology \& Neurobiology 160(3):320-324. https://doi. org/10.1016/j.resp.2007.10.016

Andersson, J. P., Liner, M. H., Fredsted, A., and Schagatay, E. K. 2004. Cardiovascular and respiratory responses to apneas with and without face immersion in exercising humans. Journal of Applied Physiology 96(3):1005-1010. https://doi.org/10.1152/japplphysiol.01057.2002

Andersson, J.P., Liner, M. H., Runow, E., and Schagatay, E. K. 2002. Diving response and arterial oxygen saturation during apnea and exercise in breath-hold divers. Journal of Applied Physiology 93(3):882-886. https://doi. org/10.1152/japplphysiol.00863.2001

Baranova, T. I. 2004. Characteristics of the human cardiovascular system in the human diving response. Russian Journal of Physiology 90:20-31.
Baranova, T.I., Berlov, D. N., Glotov, O.S., Korf, E. A., Minigalin, A. D., Mitrofanova, A. V., Ahmetov, I. I., and Glotov, A.S. 2017. Genetic determination of the vascular reactions in humans in response to the diving reflex. American Journal of Physiology-Heart and Circulatory Physiology 312(3):H622-H631. https://doi.org/10.1152/ ajpheart.00080.2016

Butler, P. J. and Jones, D. R. 1997. Physiology of diving of birds and mammals. Physiological Reviews 77(3):837-899. https://doi.org/10.1152/physrev.1997.77.3.837

Campbell, L. B., Gooden, B.A., Lehman, R. G., and Pym, J. 1969. Simultaneous calf and forearm blood flow during immersion in man. Australian Journal of Experimental Biology and Medical Science 47(6):747-754. https://doi. org/10.1038/icb.1969.171

Dawson, C. A. 1984. Role of pulmonary vasomotion in physiology of the lung. Physiological Reviews 64(2):544-616. https://doi.org/10.1152/physrev.1984.64.2.544

Elsner, R. W. 1970. Diving mammals. Science Journal 6(4):6974.

Elsner, R. W., Franklin, D. L., and Vancitters, R. L. 1964. Cardiac output during diving in an unrestrained sea lion. Nature 202:809-810. https://doi.org/10.1038/202809a0

Elsner, R. W., Garey, W. F., and Scholander, P. F. 1963. Selective ischemia in diving man. American Heart Journal 65:571572. https://doi.org/10.1016/0002-8703(63)90110-8

Ferrigno, M., Hickey, D. D., Liner, M. H., and Lundgren, C. E. 1987. Simulated breath-hold diving to 20 meters: cardiac performance in humans. Journal of Applied Physiology 62(6):2160-2167. https://doi.org/10.1152/jappl.1987.62.6.2160

Galantsev, V.P. 1977. The evolution of adaptations of diving animals. L: Nauka. (In Russian)

Galantsev, V.P. 1982. Physiological adaptations of diving mammals. Ecological physiology of animals. (In Russian)

Galantsev, V.P. 1986. Adaptations of the cardiovascular system of secondary aquatic amniot. L: Leningrad State University. (In Russian)

Galantsev, V.P., Baranova,T.I., Perepelitsa, V.A., Petukhova, N. V., and Yanvareva, I. N. 1995. Dependence of adaptive cardiovascular reactions to cold hypoxic effects on the psychophysiological status of a human. Russian Journal of Physiology 81(5):89-92.

Glotov, A.S., Ivashchenko, T.E., Obraztsova, G. I., Nasedkina, T. V., and Baranov, V. S. 2007. Renin-angiotensin and kinin-bradykinin genes polymorphism effects on permanent arterial hypertension in children. Molecular Biology 41:18-25. (In Russian)

Gooden, B.A. 1994. Mechanism of the human diving response. Integrative Physiological and Behavioral Science 29(1):6-16. https://doi.org/10.1007/bf02691277

Heusser, K., Dzamonja, G., Tank, J., Palada, I., Valic, Z., Bakovic, D., Obad, A., Ivancev, V., Breskovic, T., Diedrich, A., Joyner, M.J., Luft, F. C., Jordan, J., and Dujic, Z. 2009. Cardiovascular regulation during apnea in elite divers. Hypertension 53(4):719-724. https://doi.org/10.1161/HYPERTENSIONAHA.108.127530

Ilardo, M. and Nielsen, R. 2018. Human adaptation to extreme environmental conditions. Current Opinion in Genetics \& Development 53:77-82. https://doi.org/10.1016/j. gde.2018.07.003

Irving, L. 1963. Bradycardia in human divers. Journal of Applied Physiology 18(3):489-491. https://doi.org/10.1152/ jappl.1963.18.3.489

Korpas, D., Halek, J., and Dolezal, L. 2009. Parameters describing the pulse wave. Physiological Research 58(4):473-479.

Liner, M. H. and Andersson, J.P. 2008. Pulmonary edema after competitive breath-hold diving. Journal of Applied 
Physiology 104(4):986-990. https://doi.org/10.1152/japplphysiol.00641.2007

McCulloch, P.F., Lahrman, K.A., DelPrete, B., and DiNovo, K. M. 2018. Innervation of the nose and nasal region of the rat: Implications for initiating the mammalian diving response. Frontiers in Neuroanatomy 12:85. https:// doi.org/10.3389/fnana.2018.00085

Morman, D. and Heller, L. 2000. Physiology of the cardiovascular system. Piter, St. Petersburg. (In Russian)

Palko, T. 2007. Impedance rheography for systemic and pulmonary circulation study and clinical application. IFMBE Proceedings 17:608-611. https://doi.org/10.1007/978-3-540-73841-1_157

Ponganis, P.J. 2011. Diving mammals. Comprehensive Physiology 1(1):447-465. https://doi.org/10.1002/cphy.c091003

Ramirez, J. M., Folkow, L. P., and Blix, A. S. 2007. Hypoxia tolerance in mammals and birds: from the wilderness to the clinic. Annual Review of Physiology 69:113-143. https:// doi.org/10.1146/annurev.physiol.69.031905.163111

Ronkin, M. A. and Ivanov, S. G. 1997. Rheography in clinical practice. Medicine, Moscow. (In Russian)
Scholander, P. F., Hammel, H. T., Lemessurier, H., Hemmingsen, E., and Garey, W. 1962. Circulatory adjustment in pearl divers. Journal of Applied Physiology 17:184-190. https://doi.org/10.1152/jappl.1962.17.2.184

Thompson, D. and Fedak, M. A. 1993. Cardiac responses of grey seals during diving at sea. Journal of Experimental Biology 174:139-154.

Vaillancourt, M., Chia, P., Sarji, S., Nguyen, J., Hoftman, N., Ruffenach, G., Eghbali, M., Mahajan, A., and Umar, S. 2017. Autonomic nervous system involvement in pulmonary arterial hypertension. Respiratory Research 18(1):201. https://doi.org/10.1186/s12931-017-0679-6

West, J.B. and Mathieu-Costello, O. 1992. Stress failure of pulmonary capillaries: role in lung and heart disease. The Lancet 340(8822):762-767. https://doi. org/10.1016/0140-6736(92)92301-u

West, J. B., Tsukimoto, K., Mathieu-Costello, O., and Prediletto, R. 1991. Stress failure in pulmonary capillaries. Journal of Applied Physiology 70(4):1731-1742. https://doi. org/10.1152/jappl.1991.70.4.1731 